\title{
Effect of Selective Medicinal Plant Extract on Blood Glucose, Sperm Shape and Various Physiological Parameters
}

\author{
Salla Hemadri Reddy*, Ibtisam Saif Al-Neeri, Hadeel Khalifa Al-Issaei, \\ Sara Mohammed Al-Jabri \\ Biology Section, Department of Applied Science, Higher College of Technology, Muscat, Oman \\ Email: ${ }^{*}$ hemadrisvu2020@gmail.com
}

Received 1 April 2015; accepted 8 May 2015; published 12 May 2015

Copyright (C) 2015 by authors and Scientific Research Publishing Inc.

This work is licensed under the Creative Commons Attribution International License (CC BY). http://creativecommons.org/licenses/by/4.0/

(c) (i) Open Access

\begin{abstract}
Salvadora persica, Moringa pergrina and Citrullus colocynthis are three traditional important medicinal species used in indigenous medicinal herbal drugs to cure various diseases in South Asia and Middle East countries. The objective of the present study is to investigate the effects of oral administration of extracts of Salvadora persica leaves, Moringa pergrina leaves and Citrullus colocynthis seeds on different physiological parameters of mice. The leaves of Salvadora persica, Moringa pergrina and Citrullus colocynthis seeds were collected from Ibri and Al-Musanaa, dried and crushed into powder and extract was obtained by soxhalet apparatus. The extract was then administered to mice at a dosage of $0.5 \%, 1.0 \%, 1.5 \%$ and $2.0 \%$ for twenty one days. The mice treated with different concentrations of plant extracts showed different physiological changes, Salvadora persica leaf extract at $1.5 \%$ and $2.0 \%$ showed hypo activity, grooming, prostration, while mice treated with $0.5 \%$ and $1.0 \%$ showed no effective behavioral changes. The Moringa pergrina leaf extract dosage of $0.5 \%, 1.0 \%, 1.5 \%$ and $2.0 \%$ produced significant weight loss and affected the blood sugar level. Citrullus colocynthis seed extract at $1.5 \%$ and $2.0 \%$ showed abnormal sperms shape like circular head, double head and double tails whereas at $0.5 \%$ and $1.0 \%$ exhibited normal sperm shape.
\end{abstract}

\section{Keywords}

Phytochemical Screening, Blood Sugar Level, Sperm Shape, Physiological Changes

\footnotetext{
${ }^{*}$ Corresponding author.

How to cite this paper: Reddy, S.H., Al-Neeri, I.S., Al-Issaei, H.K. and Al-Jabri, S.M. (2015) Effect of Selective Medicinal Plant Extract on Blood Glucose, Sperm Shape and Various Physiological Parameters. American Journal of Plant Sciences, 6, 11091115. http://dx.doi.org/10.4236/ajps.2015.68115
} 


\section{Introduction}

Medicine is considered as one of the most important necessities to all of us. It is derived from the Latin words medicina meaning "the art of healing". There are different types of medicines among which herbal medicine comes from different types of plants and their parts used in hospitals to treat various diseases and disorders. Bynum, W. F mentioned in 2006 in his article; “The Rise of Science in Medicine” is herbal medicine, also called botanical medicine or phytomedicine. It refers to use of any plant's seeds, berries, roots, leaves, bark, or flowers for medicinal purposes. Whole herbs contain many ingredients and it is likely that they work together to produce the desired medicinal effect [1].

There is a huge difference between natural and synthetic drugs. A natural drug is something likely to be plant form of all natural and a synthetic drug is a drug that is made or mixed with chemicals. The Natural drugs are much less harmful than those that are synthetic. When you play around with a substance and mix it with all sorts of chemicals of course it is going to be dangerous and harmful, more so than that that is natural [2]. According to world health organization survey, $75 \%$ - $80 \%$ of global population depends on plant derived medicines either in the form of any plant part or even whole plant for the medications. In addition, majority of the population in developing countries depends on medicinal plant products for primary health related problems, since herbal medicine is available in plenty and affordable. Due to the above importance of natural medicine from plants and their derivatives, the research aims to study the medicinal importance and the physiological role of selective traditional medicinal plants used in Sultanate of Oman for curing several diseases. The traditional herbal medicinal plants are used in the present study to evaluate the on blood sugar, sperm shape etc. including Salvadora persica, Citrullus colocynthis \& Moringa peregrine, since these are the three of the most commonly used medicinal plants in Sultanate of Oman to control diabetes in suburban regions according to the sources collected from villages. The plants used in the present study are Salvadora persica, Moringa pergrina and Citrullus colocynthis. Salvadora persica has been used effectively in the Indian subcontinent for the treatment of symptoms related to diabetes i.e. hyperglycemia, hyperlipidemia, etc. Arabic Salvadora persica $(250 \mathrm{mg} / \mathrm{kg})$ possesses significant hypoglycemic and hypolipidemic activities and regenerated pancreatic $\beta$-cells in streptozotocin treated diabetic rats [3]. Citrullus colocynthis (L.) Schrad fruit is an herbal medicine used by traditional herbalists for the treatment of diabetes in Iran [4]. The Egyptian plant M. peregrina is rich in biologically active ingredients which show potent cytotoxic activity and also its ethanolic extract exerts a significant antihyperglycemic effect [5].

\section{Materials and method}

\subsection{Materials}

Electronic grinder, Oven, Rotary evaporator, UV-spectrophotometer, Glucometer, Weighing balance, Microscope, Refrigerator, Ultra Sonic Processor, Micropipettes, PH Meter, chloroform, DMSo, Hcl, NaoH, Sodium citrate, Biuret reagent, BSA, Giemsa reagent, Eosin, Methanol, Leaves of Salvadora persica, leaves of Moringapergrina, Seeds of Citrullus colocynthis and white albino mice.

\subsection{Methods}

\subsubsection{Preparation of Plant Extracts}

The plant materials (Salvadora persica leaves, Moringa pergrina leaves, Citrullus colocynthis seeds) were collected from ALMusanaa city in Al-Batina Region and Ibri city in Al-Dhahira Region on 30 January 2014. Leaves and seeds were washed with tap water, then shade-dried for two weeks and ground to a fine powder with electronic grinder. The resulting powdered matter of each individual plant material was extracted by using soxhalet apparatus by taking $300 \mathrm{~g}$ of fine powder in $600 \mathrm{ml}$ of chloroform for six hours under constant temperature. The extracts of each individual were evaporated in Rota evaporator at constant temperature and pressure for 2 hrs, obtained crude extract was weighed and stored for further preparations [6].

\subsubsection{Treatment of Mice with Different Concentration of Extracts}

Four different concentrations $(0.5 \%, 1 \%, 1.5 \%, 2 \%)$ of individual extracts were prepared by dissolving one gram of each crude extract in DMSO (Dimethylsulfoxide) to obtain 1\% stock solution from which experimental concentrations are prepared in sterile distilled water and pH was adjusted to 9 [7]. 102 locally bred white male mice, initially weighing 15 - 30 g were obtained from Higher College Of Technology (HCT), Al-Khuwair, Sul- 
tanate of Oman. They were housed in group of six animals at a temperature of $25^{\circ} \mathrm{C}$. The mice were weighed and blood glucose level was measured by Glucometer by taking the blood from mice eyes prior treatment. They were fed pellets and given tap water. They were divided into five groups, each with six mice and acclimatized for 4 days prior to experimentation. Group 1, (control), was given tap water. Group 2, 3, 4, 5 were treated with different concentration of dose by oral gavage. Group 2 was treated with $0.5 \%$, Group3 was treated with $1 \%$, Group 4 was treated with $1.5 \%$, and Group 5 was treated with $2 \%$. This treatment was carried orally; $1 \mathrm{ml}$ was given by syringe for each and regularly for duration of 21 days. The mice were weighed and blood glucose level was measured by Glucometer once before treatment, then again after treatment [8].

\subsubsection{Physiological Study}

The following physiological studies were carried out namely blood glucose level, hematological, liver protein content and sperm abnormality. To study the said studies experimental mice were sacrificed by applying $20 \mathrm{ml}$ of chloroform on a cotton plug in tightly closed desiccators for a period of 5 minutes [9] and then blood, liver and testis are collected.

Body weight: All the mice were weighed prior and after treatment by using a sensitive weighing balance [9].

Blood glucose level: Blood glucose level was measured before and after treatment by taking the blood sample from the eye by using capillary tubes. The blood sample was immediately transferred on to a glass slide, and then strip which was attached to the glucometer was immersed into the blood sample. The reading was recorded in $\mathrm{m} \mathrm{mol} / \mathrm{L}[10]$.

Sperm abnormality: Testis were macerated with two forceps to get cell suspension.10 ul of the cell suspension were taken by micropipette on a slide, a drop of eosin necrosin was added to the 10 ul cell suspension and mixed well and air dried, then observed under medium power in thelight microscope [11].

\section{Results and Discussion}

\subsection{Plants Extracts}

5 grams of solid, dark green crude extracts of Salvadora persica leaves and solid, dark green Moringa pergrina leaves whereas $15 \mathrm{ml}$ of light yellow crude oil extract of Citrullus colocynthis seeds were obtained after extraction by soxhelet apparatus. Chloroform is a common solvent in the laboratory because it is relatively unreactive, miscible with most organic liquids, not flammable and conveniently volatile [12].

\subsection{Effect of Extracts on Mice Behavioral Changes}

In this study, it was found that mice treated with $0.5 \%$ and $1.0 \%$ of Salvadora persica leaves and Moringa pergrina leaves and Citrullus colocynthis seeds extract showed no distinct behavioral changes, while those treated with $1.5 \%$ of the above mentioned extracts showed multiple behavioral changes including: hypoactive asthenia, grooming and react vigorously during the oral route administration just after 21 days. Similarly, mice treated with $2.0 \%$ of the previously mentioned extracts showed similar multiple behavioral changes like reduction of motor activity, sedation, horripilation, asthenia, grooming, pileroerection and difficult to breathe after two hours of drug administration. Behavioral changes such as hypoactive-asthemia and prostration were previously reported following acute and chronic treatment of Salvadora persica leaves and Moringa pergrina leaves and Citrullus colocynthis seeds extract. The observed reduction in the activity and behavioral changes of the mice at higher dose of extract may be due to the reduction of food intake by the mice which probably has affected the function of many organ systems of mice.

\subsection{Physiological Study}

\subsubsection{Effect of Extract on Weight of the Mice}

At the end of the experiment, as it is given in Table 1, the control mice gained body weight by the percentage of 13.9\% (21.96 g to 25.5 g), whereas mice treated with the Salvadora persica leaves extract lost body weight by a percentage of $8.42 \%$ (23.43 g to $20.34 \mathrm{~g}$ ). As the concentration of extract increased the body weight loss increased $\left(\mathrm{R}^{2}=0.88\right)$. Table 1 showed that mice treated with Moringa pergrina leaf extract lost weight by the percentage of $1.1 \%$ (22.48 $\mathrm{g}$ to $19.74 \mathrm{~g}$ ). As the concentration of extract increased the mice loss more body weight $\left(\mathrm{R}^{2}=0.83\right)$. Table 1 illustrated that mice lost body weight after the oral administration of Citrullus colo- 
Table 1. Body weight determination of mice before and after treatment with different concentrations of plant extract.

\begin{tabular}{ccccccc}
\hline \multirow{2}{*}{ Experimental trials } & \multicolumn{2}{c}{ Salvadora persica } & \multicolumn{2}{c}{ Moringa pergrina } & \multicolumn{2}{c}{ Citrullus colocynthis } \\
\hline & Before & After & Before & After & Before & After \\
\hline Control & $21.96 \pm 1.78 \mathrm{~g}$ & $25.49 \pm 3.47 \mathrm{~g}$ & $21.96 \pm 4.23 \mathrm{~g}$ & $25.49 \pm 3.47 \mathrm{~g} 21.96 \pm 4.23 \mathrm{~g}$ & $25.49 \pm 3.47 \mathrm{~g}$ \\
$\mathbf{0 . 5 \%}$ & $21.45 \pm 5.06 \mathrm{~g}$ & $20.47 \pm 4.65 \mathrm{~g}$ & $26.32 \pm 6.43 \mathrm{~g}$ & $24.17 \pm 3.05 \mathrm{~g} 24.64 \pm 2.97 \mathrm{~g}$ & $23.93 \pm 3.36 \mathrm{~g}$ \\
$\mathbf{1 . 0} \%$ & $22.18 \pm 2.77 \mathrm{~g}$ & $19.99 \pm 3.56 \mathrm{~g}$ & $20.77 \pm 5.98 \mathrm{~g}$ & $19.88 \pm 1.96 \mathrm{~g}$ & $29.81 \pm 3.68 \mathrm{~g}$ & $24.66 \pm 5.87 \mathrm{~g}$ \\
$\mathbf{1 . 5 \%}$ & $23.08 \pm 7.18 \mathrm{~g}$ & $19.55 \pm 2.21 \mathrm{~g}$ & $25.92 \pm 5.94 \mathrm{~g}$ & $17.67 \pm 3.03 \mathrm{~g} 27.61 \pm 2.08 \mathrm{~g}$ & $18.09 \pm 6.45 \mathrm{~g}$ \\
$\mathbf{2 . 0 \%}$ & $17.46 \pm 1.68 \mathrm{~g}$ & $16.23 \pm 1.87 \mathrm{~g}$ & $16.89 \pm 1.71 \mathrm{~g}$ & $17.24 \pm 1.06 \mathrm{~g}$ & $16.68 \pm 1.89 \mathrm{~g}$ & $14.57 \pm 2.06 \mathrm{~g}$ \\
\hline
\end{tabular}

cynthis seed extract by the percentage of $20.05 \%$ (24.69g to $20.31 \mathrm{~g})$. The correlation coefficient $\left(\mathrm{R}^{2}=0.91\right)$ revealed that increasing of the concentration, decrease the body weight. The weight loss at $2.0 \%$ concentration was much lower than that of the control indicating the suppression of the weight gain by the extract in whole three plant extracts. This indicated that the relation is directly proportion between the concentration of extract and the body weight loss. The most reduction in the body weight was administrated in Citrullus colocynthis seed extract followed by Salvadora persica leaves extract, whereas Moringa pergrina leaf extract showed the lowest reduction. The suppression of weight gain in a dose dependent manner may be attributed to the presence of anorexigenic compounds in the extracts [13].

\subsubsection{Effect of Extract on Blood Glucose Level}

Change in blood glucose on mice with the Salvadora persica leaves and Moringa pergrina leaves and Citrullus colocynthis seeds extracts are presented in Table 2. Oral administration of Salvadora persica leaf extract for 21 days showed reduction in blood glucose by $14.8 \%$. Moringa pergrina leaf extract exhibited a percentage of reduction in the blood glucose level by $58.07 \%$. While $23.5 \%$ reduction in blood glucose was obtained with $\mathrm{Ci}$ trullus colocynthis seeds extract. There was inversely proportional relationship between increasing of concentration and the blood glucose level as it was revealed by correlation coefficient; Salvadora persica leaf extract $\left(\mathrm{R}^{2}=\right.$ 0.93), Moringa pergrina leaf extract $\left(\mathrm{R}^{2}=0.98\right)$ and Citrullus colocynthis seeds extract $\left(\mathrm{R}^{2}=0.85\right)$. The most reduction in the blood glucose level was administrated in Moringa pergrina leaf extract followed by Citrullus colocynthis seeds extract, whereas Salvadora persica leaf extract showed the lowest reduction.

A study was carried on the effect of Moringa pergrina on the blood glucose levels in 2013. The glucose lowering action of the $M$. pergrina leaf extract was found to be significant $(\mathrm{P}<0.05)$. The significant decrease in the blood glucose levels in treated mice with the extracts compared with control may be by stimulation of residual pancreatic mechanism or by probably increasing peripheral utilization of glucose. The study validates scientifically the widely claimed use of the above plant extracts as medicine to treat diabetes mellitus.

Table 2. Average blood glucose level before and after treatment.

\begin{tabular}{cccccc}
\hline & \multicolumn{2}{c}{ Salvadora persica } & \multicolumn{2}{c}{ Moringa pergrina } & \multicolumn{2}{c}{ Citrullus colocynthis } \\
\cline { 2 - 6 } Treatments & Before & after & Before & After & Before \\
\cline { 2 - 6 } Control & $4.7 \pm 0.58$ & $4.7 \pm 0.15$ & $6.8 \pm 2.48$ & $5.9 \pm 0.20$ & $6.8 \pm 0.49$ \\
$\mathbf{0 . 5 \%}$ & $4.6 \pm 0.45$ & $4.5 \pm 0.11$ & $7.6 \pm 0.46$ & $2.9 \pm 0.40$ & $6.6 \pm 0.66$ \\
$\mathbf{1 . 0 \%}$ & $4.5 \pm 0.70$ & $4.1 \pm 0.22$ & $5.4 \pm 0.94$ & $2.7 \pm 0.15$ & $7.7 \pm 2.06$ \\
$\mathbf{1 . 5 \%}$ & $4.9 \pm 0.53$ & $4.0 \pm 0.17$ & $5.5 \pm 0.65$ & $2.3 \pm 0.17$ & $7.45 \pm 2.00$ \\
$\mathbf{2 . 0 \%}$ & $5.2 \pm 0.70$ & $3.7 \pm 0.13$ & $5.3 \pm 0.65$ & $2.1 \pm 0.27$ & $8.85 \pm 1.64$ \\
\hline
\end{tabular}

Note: all the values expressed in the table are mean values of 5 samples and are $\mathrm{m} \mathrm{mol} / \mathrm{L}$.

\subsubsection{Effect of Extracts on Sperm Shape and Size}

Normal sperm have a long tail and an oval head. Abnormal sperm is characterized by having abnormal head and 
tail structures. The head may be too large or too small. The tail can be crooked or even double. These sperm abnormalities affect the sperm's ability to swim and fertilize the egg. Abnormal sperm morphology causes male infertility and it's one of the reasons why some couples cannot conceive. Most infertile men have a low sperm count, also called oligospermia. Low sperm count is often associated with poor sperm motility. A very small percentage of male infertility is due to abnormal sperm morphology, also called teratozoospermia. This condition refers to the fact that the sperm's shape is abnormal and incapable of fertilizing the egg. Documentation of different plants for reproductive disorders has, however, been reported by researchers in various parts of the world [14] [15].

This indicates that plants constitute an important part of the primary healthcare system in developing world [16]. In our study, At the end of the experiment, the obtained sperms shapes were as below: In mice treated with Salvadora persica leaf extract as shown in Figure 1, at concentration $0.5 \%$ and $1.0 \%$, normal sperms, while in $1.5 \%$, circular head and short tail. Two tails attached to one head in $2.0 \%$. At $0.5 \%$ and $1.0 \%$ of mice treated with Moringa pergrina leaf extract exhibited normal sperms whereas ecircular head and short tail obtained in

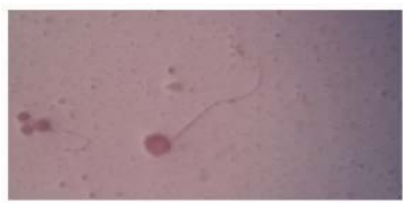

(a)

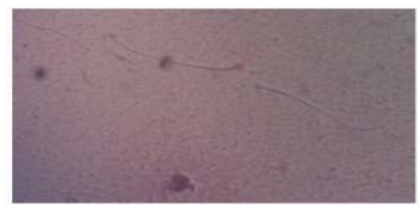

(d)

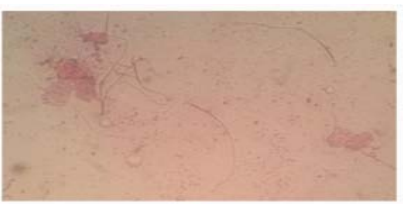

(b)

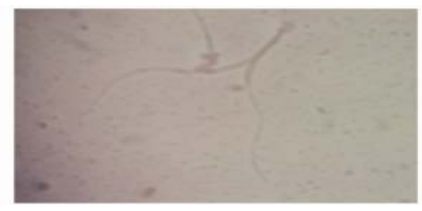

(e)

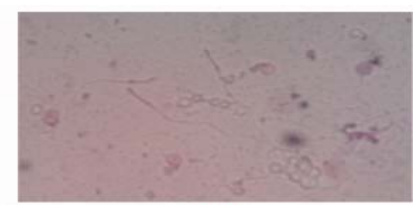

(c)

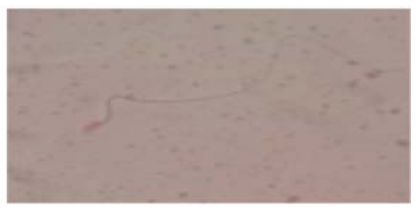

(f)

Figure 1. Observation of sperm shape and size of mice under high power treated with Salvadora persica at different concentrations (40×): (a) Control; (b) $0.5 \%$; (c) $1.0 \%$; (d) $1.5 \%$; (e) \& (f) $2.0 \%$.

1.5\%. And very long tail and circular head of sperms at $2.0 \%$ as it was administrated in Figure 2. In mice treated with Citrullus colocynthis seed extract, the sperms at $0.5 \%$ and 1.0 were normal. While at $1.5 \%$, two heads attached to one tail and small, circular head attached to long tail at $2.0 \%$ as in Figure 3 . The effect was dose dependant, that is the higher the dose the greater the effect. The fact that the extract contained some prooxidants like flavonoids, saponnins, anthraquinones, alkaloids and terpenoid suggests that the administration of the extract at higher doses of $100-1000 \mathrm{mg} / \mathrm{kg}$ body weight for two weeks may lead to oxidative damage due to free radical (FR) and reactive oxygen species (ROS) generation. The defect in sperm morphology detected in mice administered with the extract at higher doses demonstrated that the extract may have direct effect on sexual glands and sperm cells beside it pro-oxidant effect.

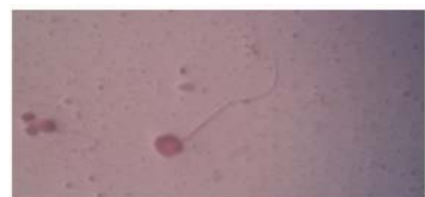

(a)

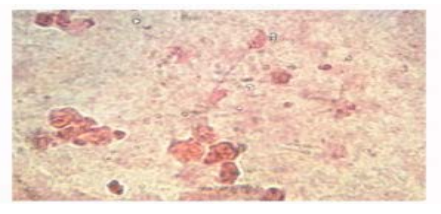

(b)

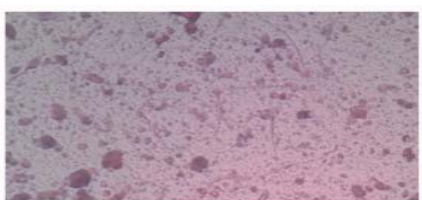

(c)

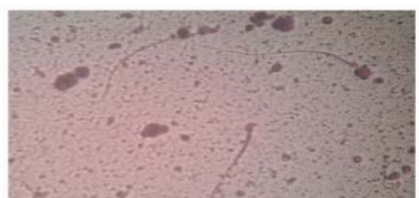

(d)

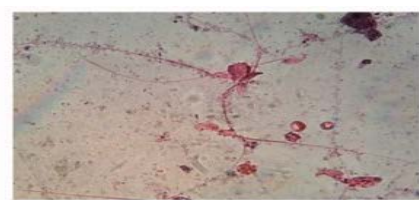

(e)

Figure 2. Observation of sperm shape and size of mice under the microscope treated with Moringa pergrinaat different concentrations (40×): (a) Control; (b) $0.5 \%$; (c) $1.0 \%$; (d) $1.5 \%$; (e) $2.0 \%$. 


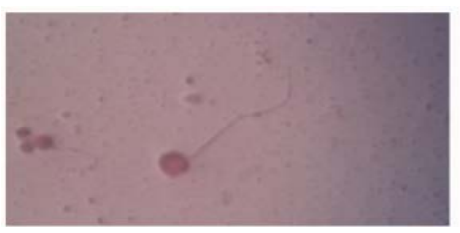

(a)

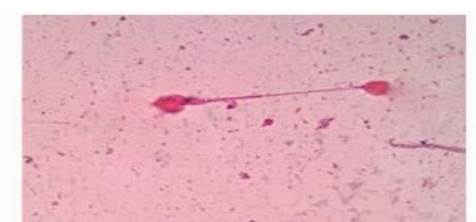

(d)

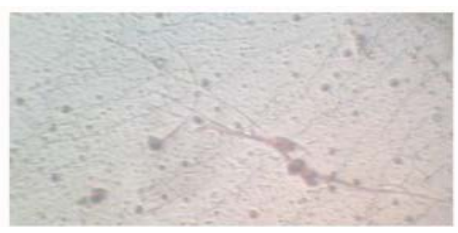

(b)

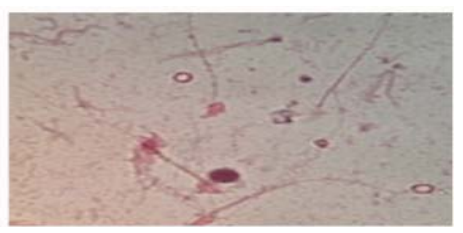

(c)

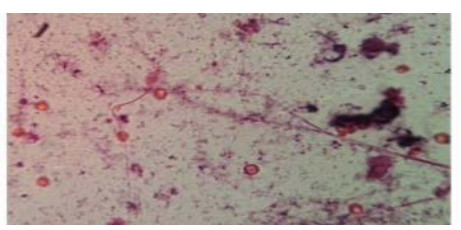

(e)

Figure 3. Observation of sperm shape and size of mice under the microscope treated with Citrullus colocynthis at different concentrations (40×): (a) Control; (b) $0.5 \%$; (c) $1.0 \%$; (d) $1.5 \%$; (e) $2.0 \%$.

\section{Conclusion}

From the thorough study, it is concluded that the three medicinal plants which are used widely for treatment of various disorders in Sultanate of Oman are found to be effective in body weight reduction and the control of blood sugar level. It is also influenced with the reproductive system. The results of the experimental mice treated with three different medicinal plant extract found to be more significant in the tested parameters. The mice treated with the Salvadora persica leaves extract lost body weight by a percentage of $8.42 \%$ (23.43 g to $20.34 \mathrm{~g}$ ), increasing the concentration of extract $(0.5 \%-2.0 \%)$ decreased the body weight of mice significantly $\left(\mathrm{R}^{2}=\right.$ 0.88 ), reduced the blood sugar level up to $14.8 \%$ \& sperm shape is also affected into circular head and short tail at higher concentration. Mice treated with Moringa pergrina leaf extract lose weight by the percentage of $1.1 \%$ (22.48 g to $19.74 \mathrm{~g})$. As the concentration of extract increases, the mice lose more body weight $\left(\mathrm{R}^{2}=0.83\right)$. Table 1 illustrates that mice lose body weight after the oral administration of Citrullus colocynthi seed extracts at the percentage of $20.05 \%$ (24.69 g to $20.31 \mathrm{~g})$. The correlation coefficient $\left(\mathrm{R}^{2}=0.91\right)$ reveals that increasing of the concentration decreases the body weight. Moringa pergrina leaf extract exhibits a percentage of reduction in the blood glucose level by $58.07 \%\left(R^{2}=0.98\right)$, while $23.5 \%\left(R^{2}=0.85\right)$ reduction in blood glucose is obtained with Citrullus colocynthis seeds extract. Both Moringa and Citrullus extracts at higher concentration 1.5\% and 2\% show sperm abnormality like very long tail and circular head while at $0.5 \%$ and $1.0 \%$ normal shape is observed. Therefore, the present study investigates all the parameters. It shows that these medicinal plants used are having potential phytochemicals, which may play a crucial role in future.

\section{Acknowledgements}

Authors are highly thankful to the Higher College of Technology, Ministry of Manpower, Sultanate of Oman for providing facilities.

\section{References}

[1] Selin, H. and Shapiro, H. (2003) Medicine across Cultures: History and Practice of Medicine in Non-Western Cultures. Springer, Berlin, 35.

[2] Askitopoulou, H., Konsolaki, E., Ramoutsaki, I. and Anastassaki, E. (2002) Surgical Cures by Sleep Induction as the Asclepieion of Epidaurus. International Congress Series, 1242, 11-17. http://dx.doi.org/10.1016/S0531-5131(02)00717-3

[3] Khan, M., Ali, M., Ali, A. and Mir, S.R. (2014) Hypoglycemic and Hypolipidemic Activities of Arabic and Indian Origin Salvadora persica Root Extract on Diabetic Rats with Histopathology of Their Pancreas. International Journal of Health Sciences (Qassim), 8, 45-56.

[4] Huseini, H.F., Darvishzadeh, F., Heshmat, R., Jafariazar, Z., Raza, M. and Larijani, B. (2009) The Clinical Investigation of Citrullus colocynthis (L.) Schrad Fruit in Treatment of Type II Diabetic Patients: A Randomized, Double Blind, Placebo-Controlled Clinical Trial. Phytotherapy Research, 23, 1186-1189. http://dx.doi.org/10.1002/ptr.2754 
[5] El-Alfy, T.S., Ezzat, S.M., Hegazy, A.K., Amer, A.M. and Kamel, G.M. (2011) Isolation of Biologically Active Constituents from Moringa peregrina (Forssk.) Fiori. (Family: Moringaceae) Growing in Egypt. Pharmacognosy Magazine, 7, 109-115. http://dx.doi.org/10.4103/0973-1296.80667

[6] Dangi, S.Y., Jolly, C.I. and Narayanan, S. (2002) Antihypertensive Activity of Total Alkaloids from the Leaves of Moringa oleifera. Journal of Pharmaceutical Biology, 40, 144-148. http://dx.doi.org/10.1076/phbi.40.2.144.5847

[7] Ali, B.H., Tanira, M.O., Bashir, A.K. and Al-Qarawi, A.A. (2000) Effect of Rhazyastricta Dence on Monoamine Oxidase and Cholinesterase Activity and Brain Biogenic Amine Levels in Rats. Journal of Pharmacy and Pharmacology, 52, 1297-1300. http://dx.doi.org/10.1211/0022357001777289

[8] Tanira, M.O., Ali, B.H., Bashir, A.K. and Chandranath, I. (1996) Some Pharmacologic and Toxicologic Studies on Rhazyastricta Dence in Rats, Mice and Rabbits. General Pharmacology, 27, 1261-1267. http://dx.doi.org/10.1016/0306-3623(95)02108-6

[9] Vadivelan, R., Dipanjan, M., Umasankar, P., Dhanabal, S.P., Satishkumar, M.N., Antony, S. and Iango, E.K. (2011) Hypoglycemic, Antioxidant and Hypolipidemic Activity of Asparagus racemosus on Streptozotocin-Induced Diabetic in Rats. Advances in Applied Science Research, 2, 179-185.

[10] Grover, J.K., Yadav, S. and Vats, V. (2002) Medicinal Plants of India with Antidiabetic Potential. Journal of Ethnopharmacology, 81, 81-100. http://dx.doi.org/10.1016/S0378-8741(02)00059-4

[11] Bayala, B., Telefo, P.B., Bassole, I.H.N., Tamboura, H.H., Belemtougri, R.G., Sawadogo, L., Malpaux, B. and Dacheux, J.L. (2011) Anti-Spermatogenic Activity Leptadeniahastata Leaf Stems Aqueous Extracts in Male Wistar Rats. Journal of Pharmacology and Toxicology, 6, 391-399.

[12] Taguchi, H. and Armarego, W.L.F. (1998) Glyceryl Ether Monooxygenase (EC 1.14.16.5). A Microsomal Enzyme of Ether Lipid Metabolism. Medicinal Research Reviews, 18, 43-88.

[13] Amole, O., Izegbu, M., Onakoya, A. and Dada, M. (2006) Toxicity Studies of the Aqueous Extract of Vernonia amygdalina. Journal of Biomedical Research, 17, 39-40.

[14] Lans, C. and Brown, G. (1998) Ethnoveterinary Medicines Used for Ruminants in Trinidad and Tobago. Preventive Veterinary Medicine, 35, 149-163. http://dx.doi.org/10.1016/S0167-5877(98)00066-X

[15] Guarrera, P.M. (2005) Traditional Phytotherapy in Central Italy (Marche, Abruzzo and Latium). Fitoterapia, 76, 1-25. http://dx.doi.org/10.1016/j.fitote.2004.09.006

[16] Al Lafi, T. and Ababneh, H. (1995) The Effect of the Extract of the Miswak (Chewing Sticks) Used in Jordan and the Middle East on Oral Bacteria. International Dental Journal, 45, 218-222. 